\title{
Investigation of sub-acute levels of zinc oxide nanoparticles on the filtration rate of Mytilaster lineatus and Dressina polymorpha in the short term
}

\author{
AMIR QADERMARZI ${ }^{1,2, \vartheta}$, MOJTABA POULADI ${ }^{1,2 \vee v}$, ALI REZAMAND ${ }^{1,2}$, SEYED HOSSEIN HOSEINIFAR ${ }^{1}$, \\ ALI AKBAR HEDAYATI ${ }^{1}$ \\ ${ }^{1}$ Department of Fisheries, Faculty of Fisheries and Environment Sciences, Gorgan University of Agricultural Sciences and Natural Resources, Gorgan, \\ Iran, Tel.: +98-9114215032, ”email: a.qadermarzi@gmail.com, Tel.: +98-9119629735, " email: mojtabafishery1987@gmail.com \\ ${ }^{2}$ Young Researchers and Elite Club, Gorgan Branch, Islamic Azad University, Gorgan, Golestan, Iran
}

Manuscript received: 18 February 2018. Revision accepted: 28 February 2018.

\begin{abstract}
Qadermarzi A, Pouladi M, Rezamand A, Hoseinifar SH, Hedayati AA. 2018. Investigation of sub-acute levels of zinc oxide nanoparticles on the filtration rate of Mytilaster lineatus and Dressina polymorpha in the short term. Nusantara Bioscience $10: 53-57$. The filtration rate is one of the physiological indices in the bivalves which indicate the degree of efficacy of the filtration function in the exposure to contaminants. In this study, changes in the filtration rate of freshwater bivalves $(D$. polymorpha and $M$. lineatus) were investigated after exposure periods of 5 and 10 days with nanoparticles. Bivalves were transferred from the natural environment to the laboratory. The distribution of nanoparticles was measured by differential light scattering (DLS). Bivalves were exposed to 2.5 , 25 and $50 \mathrm{ppm}$ nanoparticles for ten days in water reservoirs. The filtration rates were significantly different in the treatments compared to the control samples, with the highest filtration rate was observed in the control group. On the fifth day, the highest filtration rate was obtained in the first treatment of $M$. lineatus and the lowest filtration rate was obtained in the third treatment of D. polymorphia. The highest filtration rates were observed in the first and second treatments and the lowest filtration rate was observed in the third treatment. Also, there was no significant difference in the filtration rate of $M$. lineatus in the $1^{\text {st }}$ treatment with control $(\mathrm{P}>0.05)$ on the $5^{\text {th }}$ day, but filtration rate was significantly $(\mathrm{P}<0.05)$ less than other concentrations and control group in the third treatment. On the other hand, the filtration rates on the $10^{\text {th }}$ day showed similar differences compared to the $5^{\text {th }}$ day. It could be concluded that the changes infiltration rate are an appropriate indicator for the measurement of contamination in nanoparticles.
\end{abstract}

Keywords: Biological monitoring, bivalves, filtration capability, zinc oxide nanoparticles

\section{INTRODUCTION}

Nowadays, nanoparticles with their small size and surface specific properties are widely used in different fields of science and technology (Moore 2006; Doyle et al. 2016). However, most of the nanomaterials and their related products applied in most industrial products and effluents enter into aquatic environments (Daughton 2004). This has potential effects on the decrease of environmental health. Different studies have shown that the limited bioavailability of many nanoparticles in aqueous environments occur due to their low solubility and tendency to accumulate leading to toxicity, and these substances can be toxic to many aquatic organisms (Piotrovskii and Kiselev 2006; Zuykov et al. 2013). Among various nanoparticles, zinc nanoparticles are widely used in various fields due to their simple access, low cost and specific physical and chemical properties (Umer et al. 2012; Fan et al. 2017). Despite the large production and application of zinc nanoparticles, which its effluent consequently is being released into the environment, the information about the possible effects of these substances on living organisms is limited.

Bivalves are known for their characteristics, such as stagnation and filtration of suspended particles.
Consequently, they can be used as an indicator for the accumulation of significant amounts of nanoparticles exposed to the environment (Canesi et al. 2012). Bivalves are considered as a sensitive indicator to chemical pollution (Fournier et al. 2001) because these organisms are in direct contact with contaminants in water and sediments and store high levels of contaminants in their organs (Farris and Hassel 2007). Bivalves have specific features as a biochemical indicator for monitoring aquatic habitats including their presence in coastal areas, habitability, their high absorption capacity and accumulation of contaminants in organs (Philips 1980; Green et al.1985). Several physiological measures have been taken in a wide range of studies on the effects of pollutants on bivalves (Salanki and Balogh 1989). The physiological responses of freshwater bivalves to the metal particle contaminants have been investigated (Bayne 1976; Falfushynska et al. 2015). The filtration rate is a suitable physiological parameter in the bivalve membrane, and its fluctuation reflects the effects of different levels of contamination on the existent (Azarbad et al. 2010; Fan et al. 2017). The filtration rate also indicates the filtration efficiency of bivalves (Jorgensen 1990). The study of filtration activity in bivalve is a suitable method for studying biological parameters, movement and displacement of shells and water pump 
patterns to indicate the toxicity of pollutant exposure in a short period (Kramer et al. 1989; Mouabad and Pihan 1992; Zuykov et al. 2013; Burgos-Aceves and Faggio 2017).

In the case of exposed bivalves to contaminants, the degree of filtration and oxygen uptake for the diagnosis of pathobiological stress has been used in several studies (Abel 1976; Watling 1981; Rocha et al. 2015). In general, due to the increasing use of nanoparticles and a better understanding of the biological risks and effects of them on human health, it is essential to understand the hazards of nanoparticles in aqueous environments, physicochemical properties, their bioabsorption process and toxicity amounts. Therefore, the present study was conducted to investigate the effects of different concentration of zinc metal nanoparticles on the filtration rate of bivalve species (M. linearatus and D. Polymorpha) to monitor the overexposure of nanoparticle pollutants in the environment.

\section{MATERIALS AND METHODS}

\section{Collection and maintenance of bivalves}

Bivalves ( $D$. polymorpha and $M$. linearatus) were collected from the natural environment in March 2016 and transferred to the aquaculture salon of Gorgan University of Agricultural Sciences and Natural Resources. Bivalves were kept in a 40-liter water in the aquarium which was filled with chlorinated water for ten days to adapt. Feeding was performed on daily basis using Chlorella vulgaris algae $\left(3 \times 10^{6}\right.$ cells $\left.\mathrm{L}^{-1}\right)$. Water parameter conditions during storage time were set as follows: $\mathrm{pH}: 7.42 \pm 0.35$, temperature: $22 \pm 1^{\circ} \mathrm{C}$, dissolved oxygen: $7.6 \pm 0.36 \mathrm{mg} \mathrm{L}^{-1}$ and hardness: $256 \pm 5.8 \mathrm{mg} \mathrm{L}^{-1}$.

\section{Preparation of zinc oxide nanoparticles ( $\mathrm{ZnO}-\mathrm{NPs}$ )}

Nanoparticles (nanopowder, $40 \mathrm{~nm}, 99 \%$ purity; US Research Nanomaterials, Inc.) were purchased from pioneers of Iranian Nanomaterials. In order to prepare a storage solution, nanoparticles were dispersed in distilled water (1200 $\mathrm{mg} \mathrm{L}^{-1}$ ) using ultrasonic (Top Sonics 400-A, Germany) at $400 \mathrm{rpm}$ for 20 minutes. Because nanoparticles are absorbed in aqueous solution after 24 to 48 hours, re-suspending of the stock solution was carried out daily using a homogenizer (T25 digital Ultra-turax, Germany) at a radius of $14000 \mathrm{rpm}$ for 15 minutes. The size and distribution of particles were also determined using the DLS device (ZEN 3600, Germany).

\section{Measure filtration rate}

The 5 th and $10^{\text {th }}$ days after bivalves encountered at different concentrations of nanoparticles, the filtration rate of bivalves was measured using reservoirs containing 2 liters of water with a specific algal density $(200,000$ per $\mathrm{mL})$. For this purpose, C. vulgaris algae with a density of 200,000 per $\mathrm{mL}$ were used. In a 120 -minute period with 15-minute intervals, samples were taken to determine the algal density of the water contained in the bivalvecontaining reservoirs. The number of algae was counted in the volume of harvested algae samples using a NeoBar lam. In order to determine the dry weight of bivalves in each treatment, bivalves were placed in an oven for 48 hours at a temperature of $75^{\circ} \mathrm{C}$. The filtration rate values were calculated in the time intervals using the following equation:

$$
\mathrm{V}_{\mathrm{w}}=\mathrm{V} \frac{\ln (\mathrm{CO})-\ln (\mathrm{Ct})}{\mathrm{T} \times \mathrm{W}}
$$

Vw: Filtration rate in $\mathrm{g} \mathrm{mL} \cdot \mathrm{min}^{-1}$

$\mathrm{V}$ : Volume of container in $\mathrm{mL}$

C0: Algae concentration at zero moments (number per $\mathrm{mL})$

$\mathrm{Ct}$ : concentration of algae at the end of the test (number per $\mathrm{mL}$ )

$\mathrm{T}$ : Test time in minutes

$\mathrm{W}$ : Available dry weight

\section{Statistical analysis}

One-way ANOVA was performed to test significant seasonal differences in copepod abundance, diversity and water quality parameters. Data were presented as means \pm standard error of means. All data met the parametric test assumptions (normal distribution, homogeneity of variance, independence and randomness of the data). All data were transformed by Arcsine-square root to ensure a normal distribution (Zar 1984). All statistical analysis was carried out using SPSS version 21.0.

\section{RESULTS AND DISCUSSION}

The particle size of zinc oxide solution was shown in Figure 1. Based on the measurement of $95 \%$ of the volumetric form of a colloidal solution with a particle diameter of $85 \mathrm{~nm}$, it shows that used particles were in Nano scale range. Accordingly, the distribution of zinc oxide nanoparticles in the water of reservoir tanks for bivalves was similar, and all bivalves were uniformly exposed to zinc nanoparticles.

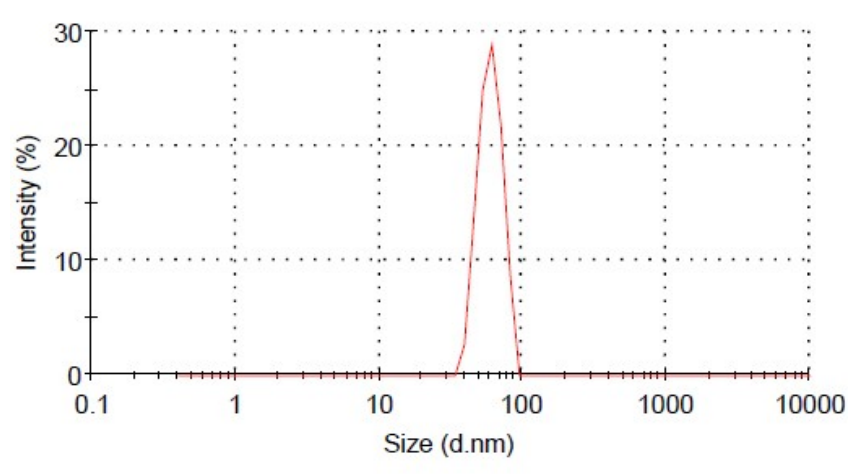

Figure 1. Distribution of $\mathrm{ZnO}$ nanoparticles in reservoir tank of bivalves 
The filtration rate and their changes in the encountered bivalves with the zinc oxide nanoparticles after 5 and 10 days exposure time during the two-hour periods were shown in Tables 1 and Figures 2 and 3. The highest filtration rates were observed in both species in control groups, which were $\left(96 \pm 27.24 \mathrm{~mL} \mathrm{m^{-1 }} \mathrm{g}^{-1} \mathrm{DW}\right)$ in $D$. polymorpha and $\left(102 \pm 17.14 \mathrm{~mL} \mathrm{~min}^{-1} \mathrm{~g}^{-1} \mathrm{DW}\right)$ in $M$. lineatus, respectively. On the 5th day, the highest levels of filtration rate in $D$. polymorpha at concentrations of 2.5 ppm and $25 \mathrm{ppm}$ from nanoparticles were $88.58 \pm 26.38$ $\mathrm{mL} \min ^{-1} \mathrm{~g}^{-1} \mathrm{DW}$ and $65.94 \pm 14.22 \mathrm{~mL} \mathrm{~min}^{-1} \mathrm{~g}^{-1} \mathrm{DW}$, respectively. Also, the lowest filtration rate was observed in the highest exposure concentrations, which was $56.05 \pm$ $12.21 \mathrm{~mL} \mathrm{~min}^{-1} \mathrm{~g}^{-1} \mathrm{DW}$.

On the fifth day in the $M$. lineatus, at a concentration of $2.5 \mathrm{ppm}$, the highest filtration level was $98.37 \pm 13.03$
$\mathrm{mL} \min ^{-1} \mathrm{~g}^{-1} \mathrm{DW}$ and the lowest filtration rate at $50 \mathrm{ppm}$ concentration was $64.05 \pm 21.11 \mathrm{~mL} \mathrm{~min}^{-1} \mathrm{~g}^{-1} \mathrm{DW}$. In $D$. polymorpha, no significant difference was observed between the filtration rate values at 2.5 and $25 \mathrm{ppm}$ with the control group, but the filtration rate in the exposure concentration of $50 \mathrm{ppm}$ was significantly $(\mathrm{P}<0.05)$ less than other concentrations and the control group. In $M$. lineatus, no significant difference was observed between the filtration rate values in the treatment with the lowest concentration in the control group, but at concentrations of 25 and $50 \mathrm{ppm}(\mathrm{P}<0.05)$ was significantly lower than the first treatment and control group. On the 10th day, differences were similar to the fifth day, so that the filtration rate in the concentration of exposure of $50 \mathrm{ppm}$ was significantly $(\mathrm{P}<0.05)$ lower in both bivalve species than in other groups.
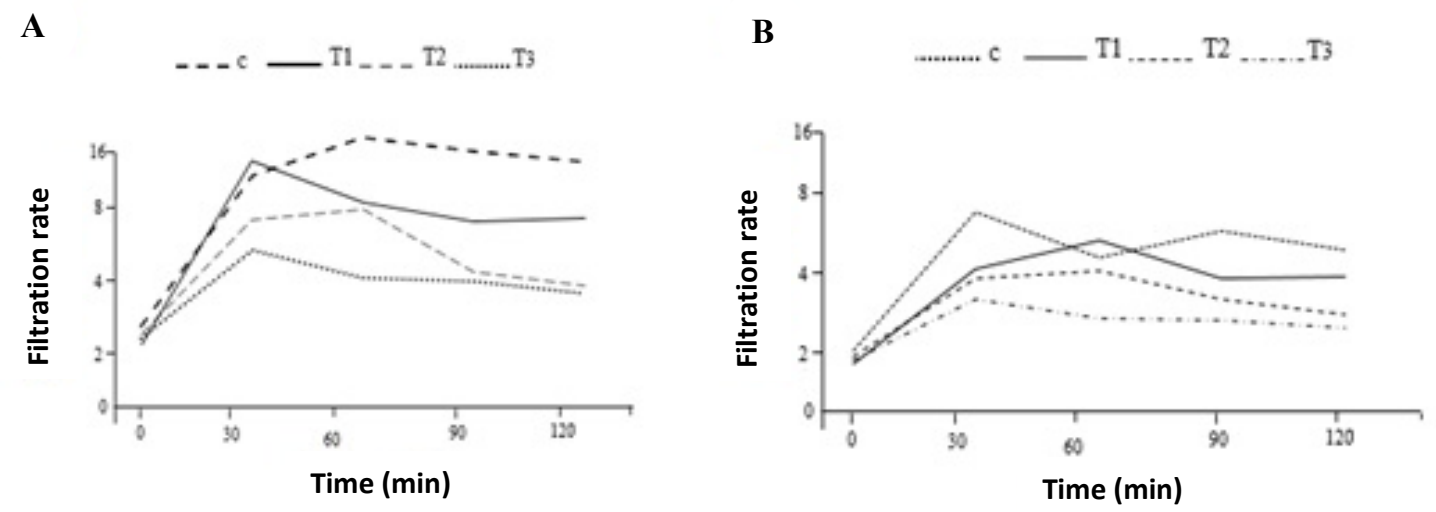

Figure 2. Filtration rate of D. Polymorpha on the (A) $5^{\text {th }}$ and (B) $10^{\text {th }}$ day of the exposure period with zinc oxide nanoparticles.

A

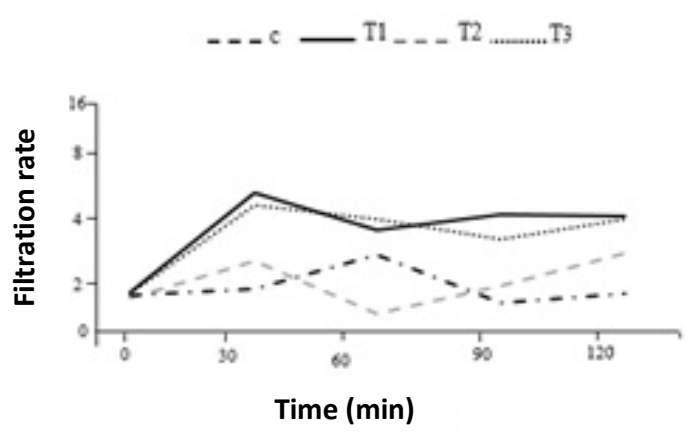

B

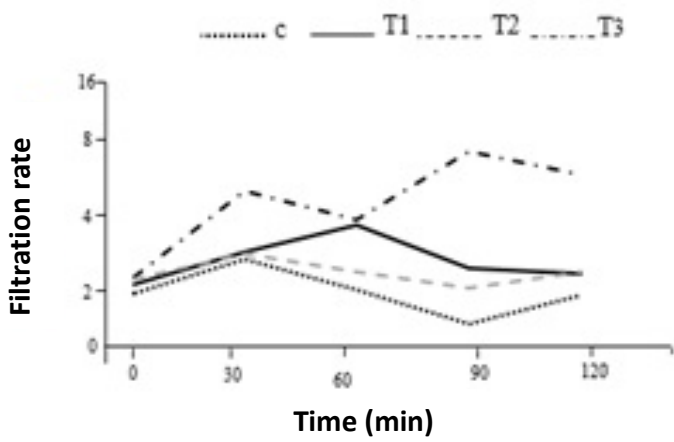

Figure 3. Filtration rate of $M$. lineatus on the (A) $5^{\text {th }}$ and (B) $10^{\text {th }}$ day of the exposure period with zinc oxide nanoparticles.

Table 1. Filtration rate $\left(\mathrm{mL} \mathrm{min} \mathrm{m}^{-1} \mathrm{~g}^{-1} \mathrm{DW}\right)$ values (mean $\pm \mathrm{SD}$ ) of control and exposed bivalves (D. Polymorpha and M. lineatus) with nanoparticles during 5 and 10 days periods.

\begin{tabular}{lccccccc}
\hline Filtration rate & Control & $\mathbf{T}_{\mathbf{1 - 5}}$ & $\mathbf{T}_{\mathbf{2 - 5}}$ & $\mathbf{T}_{\mathbf{3 - 5}}$ & $\mathbf{T}_{\mathbf{1 - 1 0}}$ & $\mathbf{T}_{\mathbf{2 - 1 0}}$ & $\mathbf{T}_{\mathbf{3 - 1 0}}$ \\
\hline D. polymorpha & $96 \pm 27.24 \mathrm{a}$ & $88.58 \pm 26.38 \mathrm{a}$ & $65.94 \pm 14.22 \mathrm{~b}$ & $56.05 \pm 12.21 \mathrm{~b}$ & $80.47 \pm 23.6 \mathrm{a}$ & $62.12 \pm 17.02 \mathrm{ab}$ & $45.61 \pm 11.81 \mathrm{~b}$ \\
M. lineatus & $102 \pm 17.14 \mathrm{a}$ & $98.37 \pm 13.03 \mathrm{a}$ & $63.34 \pm 27.22 \mathrm{~b}$ & $64.05 \pm 21.11 \mathrm{~b}$ & $21.37 \pm 19.18 \mathrm{c}$ & $73.72 \pm 15.53 \mathrm{a}$ & $49.21 \pm 10.38 \mathrm{~b}$
\end{tabular}

Note: Same letters indicate statistical non- significant difference between different species (P > 0.05); DW: Dry weight; T: Treatment 
Due to the dependence of the behavioral nature of nanoparticles in vivo and in vitro conditions, it is difficult to evaluate the biological effects of nanoparticles on several factors such as composition, size, shape, exposure, and concentration. In addition, there are several factors which influence the results of biological assessment such as insufficient control treatments, the extensive range of biological evaluations, different methods for identifying the desired concentration, and the increase and dissolve characters of nanoparticles (Bernardini et al. 2009). However, considering the increased usage of nanoscale materials, the possible effects of these materials on the health of organisms and the environment are inevitable. In recent years, environmental toxicological studies have employed a slight quantitative approach to qualitative assessments (Gornati et al. 2016). Nowadays, nanoparticle pollution is a new and dangerous problem (Shi and Wang 2004; Doyle et al. 2016). However, the use of nanoparticles is much less effective than other materials, although it also damages the environment and endangers human health. In addition, the presence of metallic nanoparticles in aquatic environments causes physiological and tissue damage to aquatic organisms (Sharmer et al. 2009).

The concentration of nanoparticles had a significant effect on filtration performance in both bivalve species. It could be observed from the lowest filtration rate in both species at both concentrations observed in the highest concentration of nanoparticles. However, on the fifth day, there was no significant difference between filtration rate values of D. polymorpha at exposure levels of 2.5 and 25 ppm compared with the control group, but the filtration rate in the exposure concentration of $50 \mathrm{ppm}$ was significantly lower than other concentrations and control group. On day 10 , the lowest filtration rate was observed in the third treatment compared to the control group and in M. lineatus, filtration rate was not significantly different in the control group with $2.5 \mathrm{ppm}$ concentration, However, the effect of other nanoparticle concentrations on the filtration rate was clearly observed and on the tenth day the same trend was repeated more strongly. Filtration rate in aquatic animals is a physiological parameter and the presence of pollutants in aquatic environments has a negative effect on this parameter. In the present study, the results showed that with increasing exposure time to nanoparticles, the filtration rate of bivalves was reduced. The rate of filtration rate and oxygen absorption for detecting the pathobiological stresses in the exposed bivalve has been used in several studies (Kramer et al. 1989). In the study of C. fluminea, it was found that filtration can be related to the oxygenation of water in this creature, which is controlled by its precise mechanism (Al-Subia et al. 2011). According to another study, exposure to $\mathrm{Cu}$ leads to a significant reduction in the filtration rate of Mytilus edulis. The reduction in the filtration rate may be due to the closure response of the shells that occurs when exposed to copper metal (Viarengo et al. 2011). According to the results of Shi and Wang (2004), exposure to copper metal has a significant reduction in the filtration rate of bivalves. In contrast, the measured filtration rate in Perna perna did not show a significant difference after 8 days of exposure to $\mathrm{Cu}$ compared to the control group. Also, in the study (Moezi et al. 2013) was found that the filtration rate of A. cygnea during the 18-day period of exposure to heavy metals had a significant decrease compared to uncontained bivalves, and by increasing the concentration of exposure, the reduction in the filtration function was higher.

In general, it can be stated that the D. polymorpha and $M$. linearatus bivalves are two suitable species for biochemical studies of contamination caused by metal particles, and in particular, the metal particles studied in this study (zinc oxide nanoparticles). The level of studied complications (bio-assembly) is a good indicator of pollution, as well as studies on the ecophysiological relationships of this species and similar organisms to nanoparticles in aquatic environments. On the other hand, these species are recommended as two suitable species for the removal of metal particles (nanoparticles and heavy metals) in wastewater treatment systems or contaminated natural environments.

\section{ACKNOWLEDGEMENTS}

Authors are thankful to Gorgan University of Agriculture Sciences and Natural Resources (GAU) for financial support and technical collaboration.

\section{REFERENCES}

Abel PD. 1976. Effects of some pollutants on the filtration rate of Mytilus. Mar Pollut Bull 7 (12): 228-231.

Al-Subia SN, Moody AJ, Mustafa SA. 2011. A multiple biomarker approaches to investigate the effects of copper on the marine bivalve mollusk Mytilusedulis. Ecotox Environ Safe 74 (7): 1913-1920.

Azarbad H, jvanshir A, Danekar A, Shapouri M. 2010. Biosorption and bioaccumulation of heavy metals by rock oyster Saccostrea cucullata in the Persian Gulf. Intl Aquat Res 2 (1): 61-69.

Bayne BL. 1976. Marine mussels; their ecology and physiology. Cambridge University Press.

Bernardini G, Cattaneo AG, Sabbioni E, Di Gioacchino M, Chiriva-Internati M, Gornati R. 2009. Toxicology of engineered metal nanoparticles. General, applied and systems toxicology.

Burgos-Aceves MA, Faggio C. 2017. An approach to the study of the immunity functions of bivalve haemocytes: physiology and molecular aspects. Fish Shellfish Immunol 67: 513-517.

Canesi L, Ciacci C, Fabbri R, Marcomini A, Pojana G, Gallo G, 2012. Bivalve molluscs as a unique target group for nanoparticle toxicity. Mar Environ Res 76: 16-21.

Daughton CG. 2004. Non-regulated water contaminants: emerging research. Environ Impact Asses Rev 24 (7): 711-732.

Doyle JJ, Ward JE, Mason R. 2016. Exposure of bivalve shellfish to titania nanoparticles under an environmental-spill scenario: Encounter, ingestion and egestion. J Mar Biol Assoc UK 96 (1) 137 149.

Falfushynska H, Gnatyshyna L, Yurchak I, Sokolova I, Stoliar O. 2015. The effects of zinc nanooxide on cellular stress responses of the freshwater mussels Unio tumidus are modulated by elevated temperature and organic pollutants. Aquat Toxicol 162: 82-93.

Fan X, Wang P, Wang C, Hu B, Wang X. 2017. Lead accumulation (adsorption and absorption) by the freshwater bivalve Corbicula fluminea in sediments contaminated by $\mathrm{TiO} 2$ nanoparticles. Environ Pollut 231: 712-721.

Farris JL, Van Hassel JH. 2007. Freshwater Bivalve Ecotoxicology, Society of Environmental Toxicology and Chemistry (SETAC). 
Fournier M, Pellerin J, Clermont Y, Morin Y, Brousseau P. 2001. Effects of in vivo exposure of Myaarenaria to organic and inorganic mercury on phagocytic activity of haemocytes. Toxicology 161 (3): 201-211.

Gornati R, Pedretti E, Rossi F, Cappellini F, Zanella M, Olivato I, Sabbioni E, Bernardini G. 2016. Zerovalent Fe, Co and Ni nanoparticle toxicity evaluated on SKOV-3 and U87 cell lines. J App Toxicol 36 (3): 385-93.

Green RH, Singh SM, Bailey RC. 1985. Bivalve mollusks as response systems for modeling spatial and temporal environmental patterns. Sci Total Environ 46 (1-4): 147-169.

Jørgensen CB. 1990. Bivalve Filter Feeding: Hydrodynamics, Bioenergetics, Physiology and Ecology, Olson \& Olson. Fedensborg, Denmark.

Kramer KJM, Jenner HA, Zwaet D. 1989. The valve movement response of mussels: a tool in biologica monitoring. Hydrobiologia 188/189: 433-443.

Moezi F, Javanshir A, Eagderi S, Pourbagher H, Sallaki M. 2013. Evaluation of bivalve clearance (CR) as a physiological indicator of heavy metal toxicity in freshwater mussel, Anodontacygnea (Linea, 1876). Sci J Anim Sci 2 (4): 89-94

Moore MN. 2006. Do nanoparticles present ecotoxicological risks for the health of the aquatic environment? Environ Int 32 (8): 967-976.

Mouabad A, Pihan JC. 1992. The pumping behavior response of Dreissena polymorpha to pollutants: a method for toxicity screening. In: Neumann and Jenner, The zebra mussel Dreissena polymorpha. Limnol Aktuell 4: 147-154.

Philips DJH. 1980. Quantitive aquatic biological indicators, their use to monitor trace metal and organochlorine pullotion. Applied Science Publication, London.
Piotrovsky LB, Kiselev OI. 2006. Fullerenes in Biology. Rostok, St. Petersburg, Russia. 336: 3.

Rocha TL, Gomes T, Sousa VS, Mestre NC, Bebianno MJ. 2015. Ecotoxicological impact of engineered nanomaterials in bivalve molluscs: an overview. Mar Environ Res 111: 74-88.

Salanki J, Balogh K. 1989. Physiological background for using freshwater mussels in monitoring copper and lead pollution. Hydrobiologia 188: 445-454.

Sharmer VK, Yngard RA, Lin Y. 2009. Silver nanoparticles: Green synthesis and their antimicrobial activities. Adv Colloid Interfac 145:83-96.

Shi D, Wang WX. 2004. Modification of trace metal accumulation in the green mussel Pernaviridis by exposure to $\mathrm{Ag}, \mathrm{Cu}$ and $\mathrm{Zn}$. Environ Pollut 132 (2): 265-277.

Umer A, Naveed S, Ramzan N. 2012. Selection of a suitable method for the synthesis of copper nanoparticles. NANO Brief Rep Rev 7 (5): 118 .

Viarengo A, Zinicchi G, Moore MN, Orunesu M. 2011. Accumulation and detoxification of copper by the mussel Mytilus galloprovincialis Lam: a study of the subcellular distribution in the digestive gland cells. Aquat Toxicol 1 (3):147-157.

Watling H. 1981. The effects of metals on mollusc filtering rate. T Royal Soc S Afr 44 (3): 441-451.

Zar JH. 1984. Bioststistical Analysis, 2nd ed. Prentice Hall Inc., New York.

Zuykov M, Pelletier E, Harper DA. 2013. Bivalve mollusks in metal pollution studies: from bioaccumulation to biomonitoring. Chemosphere 93 (2): 201-208. 